\title{
Effects of Chronic Gastritis on Sleep and Quality of Life in Adolescents
}

\author{
(D) Yeliz Çağan Appak1, (1) Gonca Özyurt22, (1) Miray Karakoyun³, (1) Maşallah Baran1,4
}

1University of Health Sciences, İzmir Tepecik Training and Research Hospital, Clinic of Pediatric Gastroenterology, İzmir, Turkey 2izmir Katip Çelebi University Faculty of Medicine, Department of Child and Adolescent Psychiatry; University of Health Sciences, Tepecik Training and Research Hospital, Clinic of Child and Adolescent Psychiatry Izmir, Turkey

${ }^{3}$ Ege University Faculty of Medicine, Department of Pediatric Gastroenterology, İzmir, Turkey

4 İzmir Katip Çelebi University Faculty of Medicine, Department of Pediatric Gastroenterology, İzmir, Turkey

\begin{abstract}
Aim: This study aims to evaluate the sleep quality and the quality of life (QoL) of adolescents with chronic gastritis, and determine the related factors.

Materials and Methods: This study included patients who were diagnosed with chronic gastritis both clinically and histopathologically. The Pittsburgh Sleep Quality Index and Epworth Sleepiness scale were used to assess sleep quality, and the Pediatric Quality of Life Inventory was used to assess QoL. The control group included healthy volunteers with no chronic diseases and no gastrointestinal system complaints.

Results: Fifty-six patients with gastritis and 55 healthy volunteers were included. The patients with gastritis were found to have significantly lower overall QoL subscale, and total scale scores, except for the social functioning total score. Except for the subjective sleep quality, significant differences were seen between the groups in the sleep quality subscale, total scale, and sleepiness scale averages. The total score of the sleep quality scale was significantly higher in patients who had lower incomes than expenditure. There were no significant differences between the obese or overweight patients with gastritis and the rest of the gastritis patients in the study sample. There were no significant differences found between the Helicobacter pylori positive and negative gastritis patients in terms of the total QoL and sleepiness scale scores.

Conclusion: This study is important because it is the first study in adolescents in this respect. The sleep and QoL scores of those adolescents with chronic gastritis were lower than the control group.
\end{abstract}

Keywords: Gastritis, quality of life, sleep, adolescent

\section{Introduction}

Gastritis is defined as the inflammation of gastric mucosa with microscopic evidence (1). Gastritis and peptic ulcer disease are the results of an imbalance between the mucosal defensive and aggressive factors. Gastritis and peptic ulcer disease can be divided into two major categories: namely primary and secondary (such as hypersecretory conditions, stress, granulomatous and immunologic/allergy situations) on the basis of the underlying etiology (2). Most cases of primary or unexplained gastritis are now known to be caused by Helicobacter pylori (H.pylori) (3). Data on acid secretion in children are limited and not up to date and their interpretations complicated by the considerable overlap in acid secretion between children with and without ulcers 
(4). There are no accurate figures related to the precise incidence of gastritis in children. As for ulcer disease, $\mathrm{H}$. pylori is probably no longer the major cause of gastritis in many parts of the world (5). In a prospective study of 100 children who underwent upper gastrointestinal system (GIS) endoscopy due to dyspeptic symptoms, 79\% were found to have gastritis (none had ulcer disease), of whom only $33 \%$ had H. pylori infection (6).

The Sydney classification of gastritis aims to combine topographic, morphologic, and etiologic information to form a clinically relevant scheme (7). This classification and grading, which now incorporates the use of a visual analogue scale, is accepted as the standard research method by which all gastric biopsies from adult patients are commonly assessed (8). The updated Sydney system is currently the most widely accepted classification for gastritis, even in children (8).

In gastritis cases, the etiological factors and the patient's response to the inflammation may change the clinical findings. Inflammation of the gastric mucosa is among the most frequent causes of abdominal pain in children (9). Gastritis can affect an individual's daily activities, and this creates an important health problem from both the social and economic points of view. Gastritis may lead to an observable worsening in the quality of life (QoL) and affect the quality of sleep for adult patients $(10,11)$. There are no studies in the contemporary international literature that are focused on the quality of sleep and life in children and adolescents with gastritis. Therefore, this study aimed to conduct an evaluation of the sleep quality and life quality of children and adolescents with gastritis and identify the relevant factors.

\section{Materials and Methods}

\section{Study Population}

This study included patients between the ages of 13 and 18 years old who applied to İmir Tepecik Training and Research Hospital Pediatric Gastroenterology Clinic between August 2017 and October 2017 and received clinical and histopathological chronic gastritis diagnoses. These patients underwent upper GIS endoscopies; gastric biopsy samples were taken from the antrum and corpus due to gastrointestinal symptoms (such as chronic abdominal pain, dyspepsia, vomiting, and abdominal distention) that had been ongoing for at least one month (8). Patients diagnosed with a disease other than gastritis via clinical, endoscopic, and histopathologic findings (such as eosinophilic esophagitis, reflux esophagitis, or inflammatory bowel disease) were not included in this study. In the literature, it has been shown that children may experience impaired QoL and sleep in different chronic diseases (12-14). For this reason, gastritis patients with additional chronic diseases were excluded from this study. Upper gastrointestinal endoscopy biopsies were assessed according to the Sydney classification by a pathologist. Those adolescents who were found to have chronic gastritis, with no additional chronic disease and additional histopathologic findings in the pathology reports and who agreed to participate in the study were included. The Pittsburgh Sleep Quality Index (PSQI) and Epworth Sleepiness scale (ESS) were used to evaluate sleep quality. QoL was evaluated via the Pediatric Quality of Life Inventory (PedsQL), which is suitable for this age group. Only those children who could read, understand, and complete all of the scales used were included in this study.

The data obtained was assessed via comparisons with a healthy control group. Healthy controls were selected from healthy volunteers who presented to the pediatric gastroenterology and pediatric outpatient clinics. For the comparisons, the sleep and life quality scales were applied to a group of healthy volunteers of the same age and gender who did not have any chronic diseases or GIS complaints. The patients' demographic findings, complaints during application, endoscopic findings, and $H$. pylori positivity status were identified and evaluated together with the life and sleep qualities. In addition, the relationship between the income levels of the patients and sleep quality was assessed. For this purpose, patients were divided into three groups as follows; patients whose income is lower than their expenditure, patients whose income is equal to their expenditure, and those patients whose income is higher than their expenditure, the patients were asked to state their income status accordingly. Each patient's body mass index (BMI) percentile was determined according to their age and sex, and those with $\mathrm{BMI} \geq 95$ percentile were considered as obese, while those with a BMI between the $85^{\text {th }}$ and $95^{\text {th }}$ percentile were classified as overweight (15). In addition, the relationship between BMI and the life and sleep qualities were assessed. Healthy volunteers with normal $\mathrm{BMI}$ ratios that ranged between the $5^{\text {th }}$ and $95^{\text {th }}$ percentiles were included in the control group. Children who were not in the 5 to 95 percentile range were not included in the control group. Neither the patient nor control groups had any drug use or acid suppressive treatment history and did not have any diseases that could affect sleep quality, such as sleep apnea. 
The study was approved by the University of Health Sciences, İmir Tepecik Training and Research Hospital Ethics Committee (approvel number: 17.08.2017/18). Consent form was filled out by all participants.

\section{Study Scales}

\section{Pediatric Quality of Life Inventory}

The PedsQL was developed for children, and it is a widely used, straight forward, and generic QoL measure that can be implemented in a short time period (16). There are two different scale forms, a self-reported scale and a parent-reported scale. Each scale is modified according to the following age groups; 2-4, 5-7, 8-12, and 13-18 years-old and the modifications were designed by accounting for the characteristics of each age group. The scale consists of four subgroups that aim to question physical, emotional, social, and school related functions. The self-reported and parent-reported forms each consist of 23 items. The score of these items is linearly converted to a value between 0 and 100 , and a higher number of points indicate a higher QoL. A Turkish validity and reliability study of the PedsQL has been conducted for adolescents (17).

\section{Pittsburgh Sleep Quality Index}

The PSQI is a self-reported scale consisting of 19 items that evaluate sleep quality and sleep disorders over the last month. Each component is scored between 0 and 3 points, and a total of 7 components (subjective sleep quality, sleep latency, sleep duration, habitual sleep efficiency, sleep disturbances, use of sleep medication, daytime dysfunction) give the total score of the scale. A total point score of over 5 indicates "bad sleep quality" (18). The Turkish version of the PSQI was developed by Agargun et al. (19).

\section{Epworth Sleepiness Scale}

The ESS is an 8-item self-administered scale that is easy to use. It evaluates the general sleepiness of an individual in 8 different daily life situations. The ESS score ranges between 0 to 24 and a higher ESS score indicates greater daytime sleepiness (20). The ESS has a high sensitivity and a high specificity with a cut-off score of more than 10 indicating an abnormal level of daytime sleepiness (21). The Turkish validity and reliability study of the ESS was conducted by Izci et al. (22).

\section{Statistical Analysis}

The quantitative variables are expressed as the mean and standard deviation, while the categorical variables are expressed as numbers and percentages. The conformity assessment of the normal distribution of the numerical data for a single sample was performed using the Shapiro-Wilk test. Bivariate comparisons were conducted with chi-square test (with Yates' and Fisher's corrections when needed), and for the independent groups, Student's t-test or MannWhitney $U$ test was used depending on the distribution. Bivariate correlations were conducted with Pearson's or Spearman's correlation analyses depending on the normal distribution. All of the statistical tests were performed with the Statistical Package for the Social Sciences version 18.0 (SPSS, Inc., Chicago, IL, USA). A p value of less than 0.05 was considered as statistically significant.

\section{Results}

This study focused on 56 patients with chronic gastritis and 55 healthy volunteers. The age and gender distributions of the patient and control groups were similar (Table I). At the time of presentation to the hospital, $60.7 \%$ of the patients with gastritis presented with complaints of dyspepsia, 30.4\% had abdominal pain, 30.4\% had vomiting, $17.9 \%$ had nausea, and $10.7 \%$ presented with complaints of abdominal distention. Endoscopic assessment revealed that 34 patients $(60.7 \%)$ had pangastritis and 22 patients (39.3\%) had antral gastritis. There was no statistical difference between the complaints of those children who had pangastritis and those children who had antral gastritis according to the chi-square analysis ( $p=0.758, z=6.548)$. Also, three patients had bulbus ulcers and one patient had an antral ulcer. Similarly, no statistically significant difference was found between the complaints of adolescents with or without ulcer $(p=0.909 z=0.958)$. The upper GIS

Table I. Socio-demographic data of the patients and controls

\begin{tabular}{|c|c|c|c|}
\hline & Patients & Controls & $\mathrm{p}$ value \\
\hline Age (mean years $\pm S D$ ) & $15.48 \pm 1.61$ & $14.94 \pm 1.79$ & 0.101 \\
\hline \multicolumn{4}{|l|}{ Gender } \\
\hline Girls (n, \%) & $34(60.7 \%)$ & $28(50.9 \%)$ & \multirow[t]{2}{*}{0.253} \\
\hline Boys (n, \%) & $22(39.3 \%)$ & $27(49.1 \%)$ & \\
\hline $\begin{array}{l}\text { Body mass index } \\
\text { percentile }(\text { mean } \pm S D)\end{array}$ & $38.7 \pm 36.5$ & $54.5 \pm 26.2$ & 0.01 \\
\hline \multicolumn{4}{|l|}{ Economic condition } \\
\hline $\begin{array}{l}\text { Less income than } \\
\text { expenditure }(n, \%)\end{array}$ & $24(42.9 \%)$ & $16(29.1 \%)$ & \multirow[t]{3}{*}{0.74} \\
\hline $\begin{array}{l}\text { Equivalent income and } \\
\text { expenditure }(n, \%)\end{array}$ & $19(33.9 \%)$ & $16(29.1 \%)$ & \\
\hline $\begin{array}{l}\text { More income than } \\
\text { expenditure }(n, \%)\end{array}$ & $13(23.2 \%)$ & $23(41.8 \%)$ & \\
\hline
\end{tabular}

SD: Standard deviation 
endoscopy biopsy samples of the patients were evaluated histopathologically, and it was determined that 48 (85.7\%) of the patients had non-atrophic pangastritis, $6(10.7 \%)$ had antral predominant non-atrophic gastritis, and $2(3.6 \%)$ had atrophic pangastritis.

It was determined that those patients with gastritis had lower scores than the healthy controls, which was statistically significant in all the QoL subscale scores and in the total scale score, with the exception of the social functioning total score (Table II). A comparison of the sleep quality of the gastritis patients with that of the healthy control group showed that there was a statistically significant difference between the two groups in all the subscale scores and the total scale score averages, except for subjective sleep quality (Table III). There was no statistically significant relationship between sleep quality and symptoms $(r=-0.069, p=0.612)$. Moreover, the average sleepiness scale score of the gastritis patients was significantly higher than the average of the healthy controls (Table III). A comparison between the female and male patients suggested that there was not a statistically significant difference between the genders regarding their QoL, sleep quality, and sleepiness total scale scores ( $p=0.27, p=0.07$, and $p=0.6$, respectively).

There was no significant difference between the patient and the control groups regarding their income and expenditure (Table I). Also, no statistically significant difference was found between the groups according to their economic conditions concerning the average of the life quality subscale and total scale scores and the sleepiness scale score. In the patient group, the sleep quality scale total score of those with lower incomes than expenditures was meaningfully higher when compared to

Table II. Assessment of the quality of life of the gastritis patients and the healthy controls

\begin{tabular}{|l|l|l|l|}
\hline & Patients & Controls & p value* \\
\hline \multicolumn{3}{|l|}{ Pediatric Quality of Life Inventory } \\
\hline $\begin{array}{l}\text { Physical health total score } \\
\text { (mean } \pm \text { SD) }\end{array}$ & $74.1 \pm 15.65$ & $94 \pm 4.97$ & $<0.001$ \\
\hline $\begin{array}{l}\text { Emotional functioning } \\
\text { total score (mean } \pm \text { SD) }\end{array}$ & $64.82 \pm 19.9$ & $86.81 \pm 9.54$ & $<0.001$ \\
\hline $\begin{array}{l}\text { Social functioning total } \\
\text { score (mean } \pm \text { SD) }\end{array}$ & $90 \pm 12.48$ & $90.81 \pm 7.97$ & 0.715 \\
\hline $\begin{array}{l}\text { School functioning total } \\
\text { score (mean } \pm \text { SD) }\end{array}$ & $62.41 \pm 20.71$ & $84.90 \pm 9.35$ & $<0.001$ \\
\hline Total score (mean \pm SD) & $72.34 \pm 15.51$ & $87.43 \pm 6.43$ & $<0.001$ \\
\hline
\end{tabular}

*Student's t-test was applied

SD: Standard deviation those whose incomes were either equal to or higher than their expenditures ( $p=0.024)$; while there was no significant difference between the sleep quality of the control group and economic conditions $(p=0.958)$. According to the Spearman correlation analysis, there was no correlation between sleep quality and socio-economic status ( $r=-$ 0.096, $\mathrm{p}=0.482$ ).

Eleven (19.6\%) of the patients with gastritis were considered to be obese or overweight. Comparisons of these patients with the other gastritis patients showed that there was no statistically significant difference regarding the QoL, sleep quality total scale score, and sleepiness scale average score $(p=0.28, p=0.17$, and $p=0.63$, respectively).

H. pylori was detected in 25 (44.6\%) of those patients who were confirmed to have gastritis via histopathology. The comparison of $H$. pylori positive patients with the $H$. pylori negative patients showed that there was no statistically significant difference between these two groups concerning the QoL and sleepiness scale total scores $(p=0.89$ and $p=0.38$, respectively). The assessment of the two groups concerning sleep quality showed that there was a statistically significant difference in the sleep duration subscale score $(p=0.029)$, but not in the other subscales and total scale scores $(p=0.96)$.

Table III. Assessment of the Pittsburgh Sleep Quality Index and Epworth Sleepiness scale results

\begin{tabular}{|l|l|l|l|}
\hline & Patients & Controls & p value** \\
\hline \multicolumn{3}{|l|}{ Pittsburgh Sleep Quality Index } \\
\hline $\begin{array}{l}\text { Subjective sleep quality } \\
\text { (mean } \pm \text { SD) }\end{array}$ & $0.09 \pm 0.39$ & $0.12 \pm 0.33$ & 0.58 \\
\hline Sleep latency (mean \pm SD) & $2.43 \pm 1.89$ & $0.46 \pm 0.64$ & $<0.001$ \\
\hline $\begin{array}{l}\text { Sleep duration (mean } \pm \\
\text { SD) }\end{array}$ & $0.50 \pm 0.68$ & $0.05 \pm 0.23$ & 0.013 \\
\hline $\begin{array}{l}\text { Habitual sleep efficiency } \\
\text { (mean } \pm \text { SD) }\end{array}$ & $0.85 \pm 0.77$ & $0.56 \pm 0.71$ & 0.04 \\
\hline $\begin{array}{l}\text { Sleep disturbances (mean } \\
\pm \text { SD) }\end{array}$ & $1.14 \pm 0.48$ & $0.80 \pm 0.40$ & $<0.001$ \\
\hline $\begin{array}{l}\text { Use of sleeping medication } \\
\text { (mean } \pm \text { SD) }\end{array}$ & $0.69 \pm 1.04$ & $0.07 \pm 0.26$ & $<0.001$ \\
\hline $\begin{array}{l}\text { Daytime dysfunction } \\
\text { (mean } \pm \text { SD) }\end{array}$ & $2.17 \pm 1.40$ & $0.21 \pm 0.45$ & $<0.001$ \\
\hline Total score (mean \pm SD) & $7.7 \pm 3.14$ & $2.5 \pm 1.5$ & $<0.001$ \\
\hline Epworth Sleepiness Scale & $4.01 \pm 2.34$ & $2.81 \pm 1.18$ & 0.001 \\
\hline $\begin{array}{l}\text { Total score (daytime } \\
\text { sleepiness) (mean } \pm \text { SD) }\end{array}$ & & & \\
\hline
\end{tabular}

${ }^{* *}$ Student's t-test was applied

SD: Standard deviation 


\section{Discussion}

Children with functional gastrointestinal disorders, such as functional abdominal pain, functional dyspepsia, and irritable bowel disease, have been reported to have significantly lower life quality than healthy controls (12). Several studies point out a deterioration in the QoL linked with chronic gastrointestinal diseases such as gastroesophageal reflux, constipation, and inflammatory bowel disease during childhood $(12,13,23)$. It has also been reported that the low QoL of children with constipation improved after they received constipation treatment (24). In another study conducted on dyspeptic pediatric patients who had esophagitis or normal histological findings, after an average of 7.6 years of follow up, it was found that during their adolescence and young adulthood period, these patients had lower QoL scores, worse dyspeptic symptoms, and more functional insufficiency when compared to a control group (25). Nevertheless, there are no studies in the literature considering life and sleep qualities together in adolescents who have gastritis.

Studies conducted on adults with gastrointestinal diseases, such as peptic ulcers and gastroesophageal reflux, have reported lower life quality scores than the normal population, but also found significantly increased life quality scores after the treatment $(26,27)$. A study on adults showed that patients with chronic gastritis had lower average scores when compared to those patients with peptic ulcers in all the life quality subscales, except for the physical functioning scale score (10). When compared with the normal population, both groups of patients had lower qualities of life scores (10). In our study, we examined the effects of gastritis on the life and sleep qualities of adolescents, and observed that those adolescents with gastritis had lower life qualities in all subscales, except for the social functioning scale score and the total score. A previous study from China that focused on adult patients with gastritis and peptic ulcers indicated that women with low-income levels had a lower QoL. The differences in the distribution of the women and men in both the patient groups were reported to affect these results (10). In our study, the QoL assessment of those patients with gastritis related to their gender and income level did not reveal a statistically significant difference.

Sleep is a fundamental and essential daily life activity that affects the life quality and health of human beings (28). Sleep quality can be affected by many factors, such as lifestyle, environmental factors, work, social life, economic conditions, general health state, and stress $(29,30)$. In our study, while sleep quality was poor in chronic gastritis patients whose expenditure was higher than their incomes, in the control group, income level had no adverse effect on sleep quality. However, the limitation of this study is that our patients were not assessed for negative factors such as a negative social environment or unhealthy living conditions (access to clean water and food, a non-hygienic living space or their nutrition characteristics). In our study, it is seen that the gastritis patients had worse sleep quality scores than the controls regarding all the subscale scores and the average of the total scale scores, except for the subjective sleep quality score. Subjective sleep quality is a component that is based on someone's interpretation of what they think about their sleep quality. The fact that our patients are not significantly different from the controls regarding subjective sleep quality may be related to their inability to interpret sleep qualities as poor or to be unaware of their sleep quality. Daytime sleepiness is an important clinical and public health problem that reduces the QoL significantly. In our study, we determined that the gastritis patients have significantly higher daytime sleepiness scale scores than the healthy controls. We think that various symptoms related to gastritis, such as abdominal pain, dyspepsia and vomiting affect the daily functioning of the individual and their daytime sleep pattern. However, in our study, when the sleep quality and the symptoms were examined, a statistically significant relationship was not found. In our study, the comparison between the male and female patients regarding their sleep quality and daytime sleepiness revealed that there was no statistically significant difference between the genders. Moreover, the detection of H. pylori in the gastritis patients did not have any effects on the QoL, daytime sleepiness, or general sleep quality, but the sleep duration was shorter when compared to the $H$. pylori negative patients.

A study conducted by Filik and Ozer (11) reported a significant relationship between gastritis or erosive esophagitis and short sleep duration in adults. This relationship was especially meaningfully higher in overweight or obese patients. It has been reported that a high BMI can lead to sleep disorders in adults and that obese patients may suffer from sleep disorders and sleeping difficulties $(31,32)$. Moreover, childhood obesity may lead to many complications that can damage QoL, such as poor academic performance, psychological findings, lifelong obesity, and cardiovascular disease (33). In one study of 144 obese and overweight children, sleep quality scores assessed via the 
PSQI and were found to be worse than those of healthy children (34). In our study, $19.6 \%$ of those patients with gastritis were obese or overweight, and their sleep qualities and qualities of life were not worse when compared to the rest of the gastritis patients in the study sample.

\section{Conclusions}

This study is important because it is the first to evaluate the QoL and sleep quality in adolescents with chronic gastritis. In our study, adolescents with chronic gastritis had poor sleep quality and lower QoL scores. The limitations of this study are the small sample size and the unevaluated negative factors such as negative social environment and unhealthy living conditions. In addition, we were not able to assess the sleep and QoL of our patients after receiving gastritis treatment. For this reason, we think that future studies evaluating chronic gastritis adolescents will be useful.

\section{Acknowledgements}

We offer our appreciation to Assoc. Prof. Dr. Ayşe Gülden Diniz (Tepecik Training and Research Hospital) for the pathological evaluations of the patients and to research assistant Büşra Emir (Katip Çelebi University) for statistical evaluation.

\section{Ethics}

Ethics Committee Approval: The study was approved by the University of Health Sciences, Tepecik Training and Research Hospital Ethics Committee (approvel number: 17.08.2017/18).

Informed Consent: Consent form was filled out by all participants.

Peer-review: Externally peer-reviewed.

\section{Authorship Contributions}

Medical Practices: Y.Ç.A., G.Ö., M.K., Concept: Y.Ç.A., G.Ö., M.K., Design: Y.Ç.A., G.Ö., M.B., Data Collection or Processing: Y.Ç.A., G.Ö., M.K., Analysis or Interpretation: Y.Ç.A., G.Ö., M.B., Literature Search: Y.Ç.A., G.Ö., M.K., Writing: Y.Ç.A., G.Ö.

Conflict of Interest: No conflict of interest was declared by the authors.

Financial Disclosure: The authors declared that this study received no financial support.

\section{References}

1. Rowland M, Bourke B. Helicobacter pylori and Peptic Ulcer Disease. Kleinman RE. Walk-er's Pediatric Gastrointestinal Disease, 6th ed, People's Medical Publishing House Ltd, North Carolina, USA, 2018;593-616.
2. Tytgat GN. Etiopathogenetic principles and peptic ulcer disease classification. Dig Dis 2011;29:454-8.

3. Koletzko S, Jones NL, Goodman KJ, et al. Evidence-based guidelines from ESPGHAN and NASPGHAN for Helicobacter pylori infection in children. I Pediatr Gastroenterol Nutr 2011;53:230-43.

4. Hyman PE, Hassall E. Marked basal gastric acid hypersecretion and peptic ulcer disease: medical management with a combination $\mathrm{H} 2$-histamine receptor antagonist and anticholinergic. J Pediatr Gastroenterol Nutr 1988;7:57-63.

5. Kalach N, Papadopoulos S, Asmar E, et al. In French children, primary gastritis is more fre-quent than Helicobacter pylori gastritis. Dig Dis Sci 2009;54:1958-65.

6. Kalach N, Mention K, Guimber D, Michaud L, Spyckerelle C, Gottrand F. Helicobacter py-lori infection is not associated with specific symptoms in nonulcer-dyspeptic children. Pediat-rics 2005;115:17-21.

7. Price AB. The Sydney System: histological division. I Gastroenterol Hepatol 1991;6:209-22.

8. Dixon MF, Genta RM, Yardley JH, Correa P. Classification and grading of gastritis. The updated Sydney System. International Workshop on the Histopathology of Gastritis, Houston 1994. Am J Surg Pathol 1996;20:1161-81.

9. Macarthur C, Saunders N, Feldman W. Helicobacter pylori, gastroduodenal disease, and recurrent abdominal pain in children. JAMA 1995;273:729-34.

10. Wen Z, Li X, Lu Q, et al. Health related quality of life in patients with chronic gastritis and peptic ulcer and factors with impact: a longitudinal study. BMC Gastroenterology 2014;14:149.

11. Filik L, Ozer N. Short sleep duration of overweight and obese patients with erosive esop-hagitis and gastritis. Indian I Gastroenterol 2015;34:408-9.

12. Varni JW, Bendo CB, Nurko S, et al. Pediatric Quality of Life Inventory (PedsQL) Gastro-intestinal Symptoms Module Testing Study Consortium. Health-related quality of life in pediat-ric patients with functional and organic gastrointestinal diseases. J Pediatr 2015;166:85-90.

13. Youssef NN, Langseder AL, Verga BJ, Mones RL, Rosh JR. Chronic childhood constipa-tion is associated with impaired quality of life: A Case-Controlled Study. I Pediatr Gastroenter-ol Nutr 2005; $41: 56-60$

14. Kostkova M, Durdik P, Ciljakova M, et al. Short-term metabolic control and sleep in chil-dren and adolescents with type 1 diabetes mellitus. I Diabetes Complications 2018;32:580-5.

15. Neyzi O, Bundak R, Gökçay G, et al. Reference values for weight, height, head circumfer-ence, and body mass index in Turkish Children. J Clin Res Pediatr Endocrinol 2015;7:280-93.

16. Varni JW, Seid M, Rode CA. The PedsQL: measurement model for the pediatric quality of life inventory. Med Care 1999;37:12639

17. Cakin Memik N, Ağaoğlu B, Coşkun, A, Uneri OS, Karakaya I. The validity and reliability of the Turkish Pediatric Quality of Life Inventory for children 13-18 years old. Turk Psikiyatri Derg 2007; 18:353-63

18. Buysse DJ, Reynolds CF, Monk TH, Berman SR, Kupfer DJ. The Pittsburgh Sleep Quali-ty Index: a new instrument for psychiatric practice and research. Psychiatry Res 1989;28:193213. 
19. Agargun $M Y$, Kara $H$, Anlar $O$. The validity and reliability of Pittsburgh Sleep Quality Index. Turk Psikiyatri Derg 1996;7:107-11.

20. Johns MW. Sleepiness in different situations measured by the Epworth Sleepiness Scale. Sleep 1994;17:703-10.

21. Johns MW. Sensitivity and specificity of the multiple sleep latency test (MSLT), the maintenance of wakefulness test and the Epworth Sleepiness Scale: failure of the MSLT as a gold standard. J Sleep Res 2000;9:5-11.

22. Izci B, Ardic S, Firat H, Sahin A, Altinors M, Karacan I. Reliability and validity studies of the Turkish version of the Epworth Sleepiness Scale. Sleep Breath 2008;12:161-8.

23. Chouliaras G, Margoni D, Dimakou K, Fessatou S, Panayiotou I, Roma-Giannikou E. Dis-ease impact on the quality of life of children with inflammatory bowel disease. World I Gastroenterol 2017;23:1067-75.

24. Dolgun E, Yavuz M, Celik A, Ergün MO. The effects of constipation on the quality of life of children and mothers. Turk J Pediatr 2013;55:180-5.

25. Rippel SW, Acra S, Correa H, Vaezi M, Di Lorenzo C, Walker LS. Pediatric patients with dyspepsia have chronic symptoms, anxiety, and lower quality of life as adolescents and adults. Gastroenterology 2012;142:754-61.

26. Glise H. Quality of Life assessments in patients with peptic ulcer during treatment and fol-low-up. Scand I Gastroenterol Suppl 1993;199:34-5.
27. Glise $\mathrm{H}$, Hallerback B, Johansson B. Quality of Life assessments in the evaluation of gas-troesophageal reflux and peptic ulcer disease before, during and after treatment. Scand / Gastroenterol. Suppl 1995;30:133-5.

28. Koulouglioti $\mathrm{C}$, Cole $\mathrm{R}$, Kitzman $\mathrm{H}$. Inadequate sleep and unintentional injuries in young children. Public Health Nurs 2008;25:106-14

29. Wolfson AR, Carskadon MA. Sleep schedules and daytime functioning in adolescents. Child Dev 1998;69:875-87.

30. Bootzin RR, Stevens S). Adolescents, substance abuse, and the treatment of insomnia and daytime sleepiness. Clin Psychol Rev 2005;25:629-44.

31. Kirkness JP. Obesity-related ventilatory phenotypes of sleepdisordered breathing. Am J Respir Crit Care Med 2014;190:853-4.

32. Pearson NJ, Johnson LL, Nahin RL. Insomnia, trouble sleeping, and complementary and alternative medicine: Analysis of the 2002 national health interview survey data. Arch Intern Med 2006;166:1775-82.

33. Orio $F$, Tafuri $D$, Ascione $A$, et al. Lifestyle changes in the management of adulthood and childhood obesity. Minerva Endocrinol 2016;41:509-15.

34. Baran RT, Atar M, Pirgon O, Filiz S, Filiz M. Restless legs syndrome and poor sleep qua-lity in obese children and adolescents. I Clin Res Pediatr Endocrinol 2018;10:131-8. 